\title{
Смоленцева T.E.
}

\section{Применение многоуровневых систем в сфере образования}

ФГБОУ ВО «Липеиякий государственный технический университет»

(Россия, Липеик)

doi: $10.18411 / l j-12-2018-135$

idsp: ljournal-12-2018-135

\section{Аннотация}

В работе рассмотрены факторы, оказывающие влияние на формирование структурных компонентов. Рассмотрены направления, по которым будет осуществляться формирование многоуровневых систем с сфере образования. На основе выводов полученных при анализе поставленных вопросов пришли к выводу, что структурирование организационных систем позволяет оптимизировать работу всей системы в целом.

Ключевые слова: многоуровневые системы, иерархические системы, уровни иерархической системы.

При формировании многоуровневых систем необходимо в первую очередь учитывать специфику рассматриваемой предметной области.

Структура системы - это организация связей и отношений между подсистемами и элементами этой системы, состав подсистем и элементов, которым обычно соответствует определенная функция [1].

Структура формирования организационной системы приведена на рисунке 1.

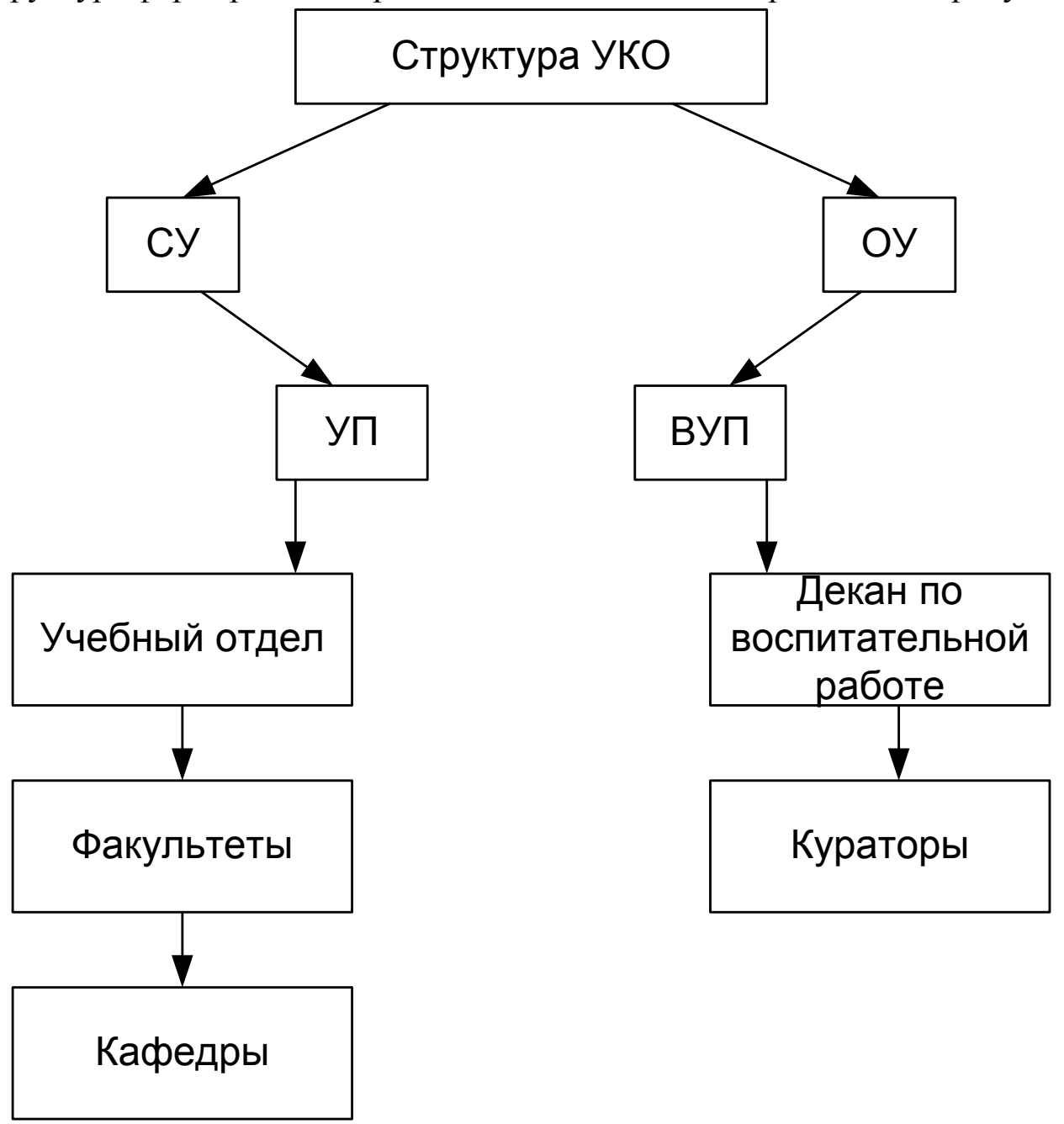

Рисунок 1 - Схема формирования организационной структуры 
Ниже представлена расшифровка представленных на рисунке 1 аббревиатур, а именно:

-

- ОУ - Объекты управления

- УП - учебный процесс

- ВУП - вне учебный процесс.

Хоть многоуровневые ИС и являются наиболее типичной формой управления, им также присущи некоторые недостатки, связанные, во-первых, с проблемой децентрализации, которая приводит к тому, что подсистемы начинают функционировать в соответствии со своими целями и могут не совпадать с целями всей системы, во-вторых, с проблемой запаздывания информации для принятия решений при переходе от одного уровня управления к другому как вверх по иерархии, так и вниз, в-третьих, с проблемой размерности, которая обуславливается большим объемом информации, циркулирующей на нижнем уровне, и необходимостью уменьшить ее, сохранив ее информативность для принятия решений, при переходе от очередного нижнего уровня к более высокому.

В процессе выявления основных компонентов системы на примере образовательных структур учитываем: основные цели и задачи образовательных учреждений. т.е. повышение качества в области образования.

Данную задачу рассматриваем по нескольким направлениям:

- повышение качества обучения;

- оптимизация процесса сбора, хранения и обработки результатов промежуточной, итоговой аттестации;

- формирование отчетной документации [2].

Для рассмотрения каждого из направлений можно сформировать модель ИС, функционирующей в динамике, такая ИС будет развиваться равномерно по каждой локальной подсистеме и пропорционально на каждый последующий период планирования.

Структурирование организационных систем позволяет оптимизировать работу не только подчиненных управляющих органов, но и функционирование объектов системы. В системе образования структурирование и оптимизация направлены на повышение качества по всем рассмотренным направлениям.

$$
* * *
$$

1. Замятина О.М. Моделирование систем / О.М. Замятина // Томск: ТПУ, 2009. - С. 204.

2. Мирошникова Т.В. Определение размерности пространства динамической системы с применением странного аттрактора / Т.В. Мирошникова // Москва: НИУ ВШЭ, №1, 2011. - С. 195-197. 